\title{
The Benefit of Hydroxyapatite-augmented Pedicle Screw Fixation in Degenerative Spondylolisthesis Patients with Osteoporosis
}

\author{
Jun Ho Lee ${ }^{1}$, Ho Yeon Lee ${ }^{2}$ \\ ${ }^{1}$ Department of Neurosurgery, Kyung Hee University Medical Center, Seoul, \\ ${ }^{2}$ Department of Neurosurgery, Spine Health Wooridul Gangbuk Hospital, Seoul, Korea.
}

Corresponding Author: Jun Ho Lee, MD, PhD Department of Neurosurgery, Kyung Hee University Medical Center, 23 Kyung Hee Daero, Dongdaemun-Gu, Seoul 02447, Korea

Tel: $+82-2-958-8405$

Fax: +82-2-958-8385

E-mail: mo09924@khu.ac.kr

Received: May 24, 2016

Revised: July 9, 2016

Accepted: July 11, 2016
Objective: A key determinant of the performance of pedicle screw systems is the strength of their attachment to the spine. The authors initially injected hydroxyapatite cement into the prepared screw hole before actual screw insertion in order to provide additional strength to this system and assessed its benefit in the fusion operation for the patients with osteoporosis. Methods: Among the 21 patients who were diagnosed as grade I degenerative spondylolisthesis on L4-5 level with osteoporosis, nine patients were treated by transforaminal lumbar interbody fusion (TLIF) with screw augmentation with hydroxyapatite and the rest 12 patients underwent TLIF only. The plain radiographs were periodically checked during and up to 2 years after the operation. The changes of the angles between the vertebral bodies, between the upper and lower screws, between the screw and lower endplate of each body, and posterior disc height changes were serially measured and compared between these two groups. Results: The angle between the upper screw and the lower endplate of upper vertebral body showed gradual decrease from $8.93^{\circ}$ to $5.79^{\circ}$ for the TLIF only group while well maintained for the augmentation group from $6.84^{\circ}$ to $6.93^{\circ}(\mathrm{p}=$ 0.053). Most of these significant angle changes occurred between 1 month and 6 months after the operation $(p<0.05)$. Conclusion: Most of the screw construct changes occurred in the upper level of fixation during 1 month to 6 months after fusion surgery in spondylolisthesis patients with osteoporosis. For these, the screw augmentation with hydroxyapatite demonstrated the improvement in maintaining the screw construct especially in the upper level of fixation.

Key Words: Hydroxyapatite, Osteoporosis, Screw augmentation

\section{INTRODUCTION}

For the past decades, pedicle screw fixation has been regarded as a standard measure to obtain a rigid internal stabilization of the unstable spine. This system has been used successfully in various degenerative spinal disorders, including spondylolisthesis and stenosis because it has the advantages of providing three-column fixation, facilitating the instrumentation of short segments, and maintaining the anatomic or desired sagittal alignment of spinal curvature. In order to achieve these merits, a firm anchorage of the screws to the vertebral bodies is required and this is directly related to the quality of bone into which screws are placed ${ }^{1,2,3)}$. Otherwise, the major complications of instrumentation such as loss of fixation or loosening of the construct might occur, especially in osteoporotic vertebrae.
Maintaining a constant screw construct would not be a simple issue after fusion surgery for the patients with osteoporosis and lots of different methods to improve the purchase of screws has been investigated using animal or cadaveric model. These include the augmentation of the screws with polymethylmethacrylate $^{4,5)}$, modification of the design of the thread, the shape, and surface of the screws ${ }^{5,6}$. Despite these devise, there were no definite description of the benefit of these augmentation in maintaining the screw construct over a certain period of time after its performance to the patients.

In the current study, we performed the fusion surgery to the patients with degenerative spondylolisthesis with screw augmentation using the hydroxyapatite and compared its result to that of those without augmentation. This hydroxyapatite has already been reported to have the advantage of being resorbed and replaced during healing and normal bone remodeling ${ }^{7,8)}$. 
Because the real parameters for measuring the screw purchase strength such as extraction torque or pull-out strength cannot be measured from the actual patients, several indirect radiographic parameters were measured to assess the maintenance of the screw construct during the each follow-up. This comparative study might provide the tip of suitability of hydroxyapatite cement for augmenting the initial fixation of screws and its advantage in maintaining a constant screw construct in senile, osteoporotic vertebrae.

\section{MATERIALS AND METHODS}

\section{Patients}

The 21 consecutive patients who were diagnosed as grade I degenerative spondylolisthesis on L4-5 level with osteoporosis and then treated with transforaminal lumbar interbody fusion (TLIF) operations between December 2002 and June 2004 at our institution with the minimum follow-up period of two years were included in this study. The diagnosis of osteoporosis was based on the measurement of bone mineral density (BMD) by T-score of less than -3.0 by dual-energy $X$-ray absorptiometry (DEXA) performed both on the femoral joint and lumbar vertebral body before operation. Among these, nine patients were treated by TLIF with screw augmentation with hydroxyapatite and the rest 12 patients were treated with TLIF only. The choice of the surgical modality was arbitrary according to the consent from the patient to pay for the extra cost for using the hydroxyapatite cement after they were explained as to the possible benefit that could be yielded by performing the screw augmentation. The augmentation group consisted of eight female and one male patient with the mean age of 66.6 years (range; 57 to 73 years) and the all twelve patients in the TLIF only group were female with the mean age of 66.9 years (range; 62 to 77 years). The mean T-scores after BMD on the lumbar vertebrae and femoral joint were -3.45 and -2.7 for the augmentation group and -3.54 and -2.7 for the TLIF only group. The detailed informations on the demographic features of both groups are listed in Table 1.

\section{Insertion of pedicle screw}

In all 21 patients regardless of the group, the TLIF operations were performed by the same senior surgeon (H.Y. Lee) in the author list. After the performance of lumbar interbody fusion using the polyethyetherketone (PEEK) cages, standard anatomical landmarks from intraoperative fluoroscopy were used for the identification of the pedicles and the confirmation of the proper position of the screws. The entry point to base of pedicle was passed by electric drill with $4 \mathrm{~mm}$-diameter burr instead of using standard awl or tapering tool to avoid injury to the cancellous portion of the pedicle even before screw insertion. Then the screw path in the body was created with 10 gauze Poverty needle (Kyeongwon Medical, Seoul, South Korea) for
Table 1. The demographic features and the measurement of bone mineral density (BMD) by T-score value on dual-energy $X$-ray absorptiometry (DEXA) for the hydroxyapatite cement screw augmentation group (patient 1 to 9) and transforaminal lumbar interbody fusion (TLIF) only group (patient 10 to 21)

\begin{tabular}{|c|c|c|c|c|c|}
\hline Patient & Sex/Age & Diagnosis & $\begin{array}{l}\text { BMD } \\
\text { spine }\end{array}$ & $\begin{array}{c}\text { BMD } \\
\text { femoral }\end{array}$ & $\begin{array}{c}\text { F/U period } \\
\text { (mos) }\end{array}$ \\
\hline 1 & $F / 61$ & L4-5 SPL & -2.81 & -2.76 & 49 \\
\hline 2 & $F / 67$ & L4-5 SPL & -3.90 & -3.13 & 45 \\
\hline 3 & $F / 64$ & L4-5 SPL & -3.67 & -3.58 & 44 \\
\hline 4 & $\mathrm{~F} / 71$ & L4-5 SPL & -3.80 & -3.00 & 42 \\
\hline 5 & $\mathrm{~F} / 73$ & L4-5 SPL & -3.30 & -2.70 & 42 \\
\hline 6 & $\mathrm{M} / 70$ & L4-5 SPL & -3.90 & -2.80 & 40 \\
\hline 7 & $F / 68$ & L4-5 SPL & -3.10 & -3.70 & 40 \\
\hline 8 & $F / 68$ & L4-5 SPL & -3.50 & -1.50 & 39 \\
\hline 9 & $F / 57$ & L4-5 SPL & -3.10 & -1.10 & 37 \\
\hline mean & 166.6 & & -3.45 & -2.70 & 42 \\
\hline 10 & $F / 62$ & L4-5 SPL & -3.40 & -1.70 & 36 \\
\hline 11 & $F / 63$ & L4-5 SPL & -3.00 & -1.00 & 35 \\
\hline 12 & $F / 63$ & L4-5 SPL & -4.31 & -3.17 & 37 \\
\hline 13 & $F / 63$ & L4-5 SPL & -3.20 & -3.30 & 34 \\
\hline 14 & $F / 64$ & L4-5 SPL & -3.40 & -2.70 & 35 \\
\hline 15 & $F / 66$ & L4-5 SPL & -3.80 & -4.00 & 32 \\
\hline 16 & $F / 68$ & L4-5 SPL & -3.10 & -1.90 & 39 \\
\hline 17 & $F / 69$ & L4-5 SPL & -3.90 & -3.10 & 42 \\
\hline 18 & $F / 69$ & L4-5 SPL & -3.40 & -3.10 & 40 \\
\hline 19 & $F / 69$ & L4-5 SPL & -4.00 & -3.50 & 32 \\
\hline 120 & $\mathrm{~F} / 70$ & L4-5 SPL & -3.20 & -1.10 & 37 \\
\hline 21 & $\mathrm{~F} / 77$ & L4-5 SPL & -3.80 & -3.80 & 36 \\
\hline mean & /66.9 & & -3.54 & -2.70 & 36.2 \\
\hline
\end{tabular}

F: female, M: male, SPL: spondylolisthesis, F/U: follow-up

vertebroplasty, which has the property of outer diameter of $3 \mathrm{~mm}$ and inner diameter of $2.2 \mathrm{~mm}$. In the nine patients who agreed with the use of hydroxyapatite cement, needle was drawn back about $1 \mathrm{~cm}$ to create a void for all pedicles. About $2 \mathrm{cc}$ of BoneSource hydroxyapatite cement (Stryker Howmedica Osteonics, Kalamazoo, Mississipi) was injected through the needle. Due to the mud-like nature of hydroxyapatite cement, tapping of inlet into the needle was necessary to achieve a complete injection. The typical mixture of these BoneSource cement consisted of liquid to powder ratio of $5 \mathrm{cc}$ to $10 \mathrm{gm}$. We usually injected the BoneSource cement just after mixing without haste because unlike PMMA cement, pedicle screws could be inserted even after full hardening of hydroxyapatite cement. Then, bilaterally for each vertebra, a $6.5 \mathrm{~mm}$ diameter and $45 \pm 5 \mathrm{~mm}$ long Diapason System Pedicle Screws (Stryker Osteonics, Allendale, New Jersey) were inserted into the pedicles. The cement was allowed to harden for 24 hours after implantation with the patient in bed rest. 


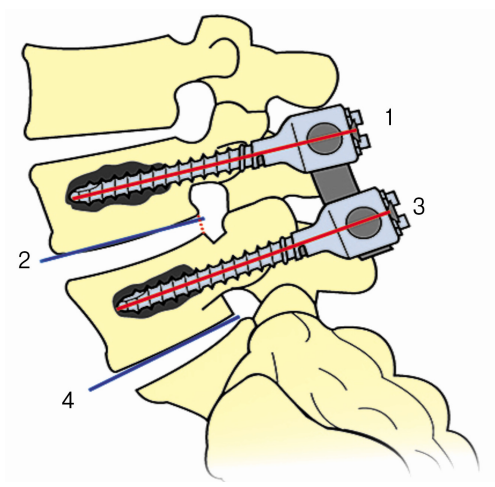

Fig. 1. The schematic illustration demonstrating our method of measuring the absolute values of the angles between the vertebral bodies at the operated level (angle formed between line 2 and 4), between the upper and lower screws (angle formed between line 1 and 3), between the inserted screw and lower endplate of corresponding vertebral body (angle formed between line 1 and 2 or line 3 and 4), and posterior disc height (dotted line) from the lateral radiographs at each corresponding period during the follow-up. The mid-axial line of each screw was used for the angle measurement.

\section{Radiological assessment}

The plain antero-posterior (AP) and true lateral radiographs were checked serially during operation, immediately after the operation, 1 month, 3 months, 6 months, 1 year, and 2 years after the operation. The absolute values of the angles between the vertebral bodies at the operated level, between the upper and lower screws, between the inserted screw and lower endplate of corresponding vertebral body, and posterior disc height changes were serially measured from the lateral radiographs of the each corresponding period. The mid-axial line of each screw was used for the angle measurement. Because the two screws inserted for each vertebral body usually were not exactly parallel to each other on plain radiography, the screws inserted on the side of laminectomy and fascetectomy during TLIF were chosen for the radiographic measurement. These radiological changes were measured with aid of the PiView program (Infinitt Co., Seoul, South Korea) and the mean values were recorded after twice respective measurement by the first author (J.H. Lee) who was not involved with surgery. For the comparison between the two groups, (1) the absolute values of the mean angle and height at each corresponding period, (2) setting the measured values during the operation as index point, the amount of changes in angles or height over the time from index point to the each period, (3) the amount of changes in angles or height between each serial period were calculated (Figs. 1 and 2).

\section{Statistical analysis}

An analysis of variance (ANOVA) was conducted to assess the significance of the differences among the values measured at each follow-up period in each group, while an independent
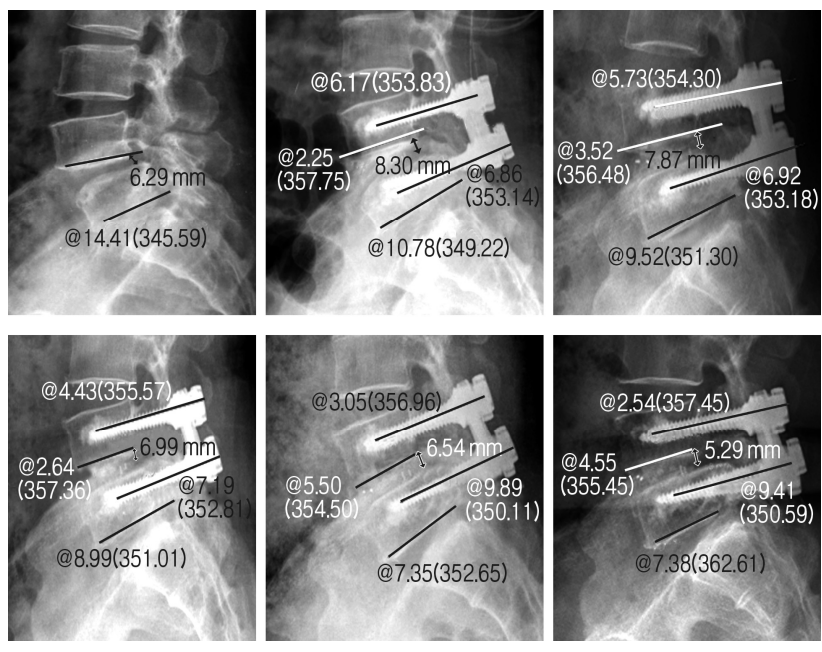

Fig. 2. An illustrative case of performing the transforaminal lumbar interbody fusion (TLIF) with screw augmentation by hy droxyapatite cement. The preoperative lateral radiograph from 57-year old female patient (case 9 from augmentation group) demonstrated grade I spondylolisthesis between $L 4$ and $L 5$ with the angle formed between the vertebral bodies to be $14.41^{\circ}$ and $6.29 \mathrm{~mm}$ of posterior disc height (upper left). The lateral radiograph taken immediately after the operation demon- strated the radioopaque traces of the cement augmentation around the screws with the angle between the vertebral bodies reduced to $10.78^{\circ}$ and the posterior disc height restored to $8.3 \mathrm{~mm}$ (upper middle). The angle formed between the screws was $6.17^{\circ}$ and the angle between the upper screw and lower end plate of $L 4$ and the angle between the lower screw and lower end plate of $L 5$ were $2.25^{\circ}$ and $6.86^{\circ}$, respectively. The serial lateral radiograph taken 1 month (upper right), 3 months (lower left), and 1 year (lower middle) after the operation demonstrate well-maintained screw construct. The lateral radiograph taken 2 years after the operation demonstrated still remaining radioopaque traces of the cement augmentation around the screws with the angle between the vertebral bodies and the posterior disc height slightly subsided to $7.39^{\circ}$ and $5.26 \mathrm{~mm}$, respectively. The angle formed between the screws was also reduced to $2.54^{\circ}$ but the angle between the upper screw and lower end plate of $L 4$ and the angle between the lower screw and lower end plate of $L 5$ were slightly increased to $4.55^{\circ}$ and $9.41^{\circ}$, respectively (lower right). However, the overall screw construct was still well-maintained.

two sample t-test and a Wilcoxon rank sum test were performed to evaluate the difference of the amount of changes that have occurred during each sequential time-interval and from index point to each period on follow-up.

\section{RESULTS}

\section{Angle changes between the vertebral bodies}

The mean angles between the vertebral bodies at the operated 
Table 2. The amount of changes of the angles $\left({ }^{\circ}\right)$ between the vertebral bodies from index point to certain period during the follow-up

\begin{tabular}{|c|c|c|c|}
\hline & $\begin{array}{c}\text { Hydroxyapatite } \\
\text { group }\end{array}$ & $\begin{array}{l}\text { TLIF only } \\
\text { group }\end{array}$ & p-value \\
\hline Intraop-immed. postop & $1.91 \pm 1.90$ & $1.31 \pm 1.18$ & $p>0.05$ \\
\hline Intraop-postop $1 \mathrm{mn}$ & $2.12 \pm 1.92$ & $2.16 \pm 1.54$ & $p>0.05$ \\
\hline Intraop - postop $3 \mathrm{mn}$ & $2.45 \pm 1.41$ & $2.53 \pm 1.61$ & $p>0.05$ \\
\hline Intraop-postop $6 \mathrm{mn}$ & $0.93 \pm 0.83$ & $2.90 \pm 1.80$ & $p=0.039^{*}$ \\
\hline Intraop-postop $1 \mathrm{yr}$ & $3.49 \pm 4.02$ & $3.44 \pm 2.01$ & $p>0.05$ \\
\hline Intraop-postop $2 \mathrm{yr}$ & $2.51 \pm 2.67$ & $2.39 \pm 1.55$ & $p>0.05$ \\
\hline
\end{tabular}

Intraop: intraoperative, immed. postop: immediately after operation, $\mathrm{mn}$ : month, yr: year

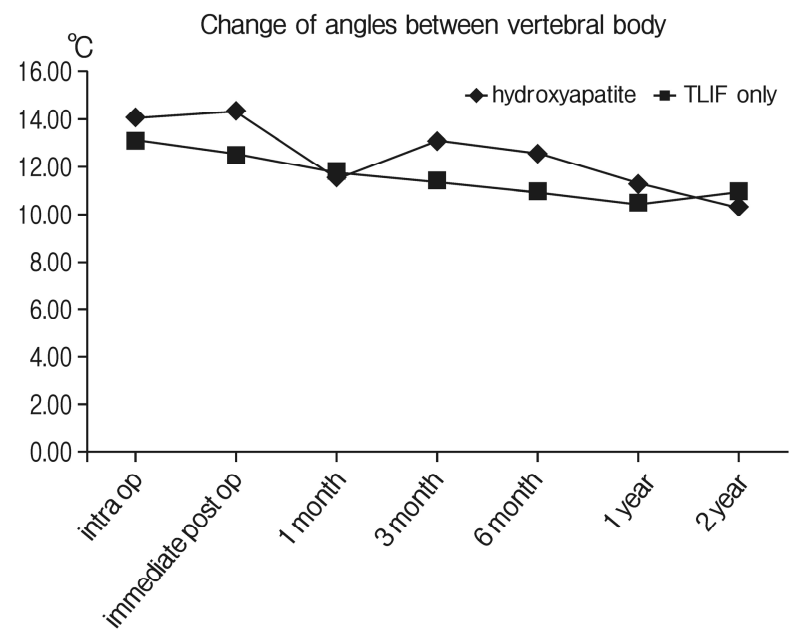

Fig. 3. The changes of angles between the vertebral bodies over serial follow-up.

level have reduced over two years of follow up from $14.09^{\circ}$ to $10.3^{\circ}$ for the hydroxyapatite augmentation group and $13.05^{\circ}$ to $10.84^{\circ}$ for the TLIF only group ( $p>0.05$ ). Of all the comparison parameters between the two groups, only the mean difference of the degree of angle reduction occurred during the period from the operation to post-operative 6 months between the two groups showed statistical significance $\left(-0.93^{\circ}\right.$ for the former vs $-2.9^{\circ}$ for the latter group, $\left.p<0.05\right)$. The results of the angle changes between the vertebral bodies for each group are summarized in Table 2 and Figure 3.

\section{Changes of the posterior disc heights}

The mean posterior disc heights between the vertebral body at the operated level have significantly reduced for each group over two years of postoperative period from $9.48 \mathrm{~mm}$ to $5.39 \mathrm{~mm}$ for the augmentation $(\mathrm{p}<0.05)$ and from $10.08 \mathrm{~mm}$ to $6.61 \mathrm{~mm}$ for the TLIF only group $(p<0.05)$. However, the amount of reduction occurred between each period or from the index point to certain postoperative period showed no significant difference

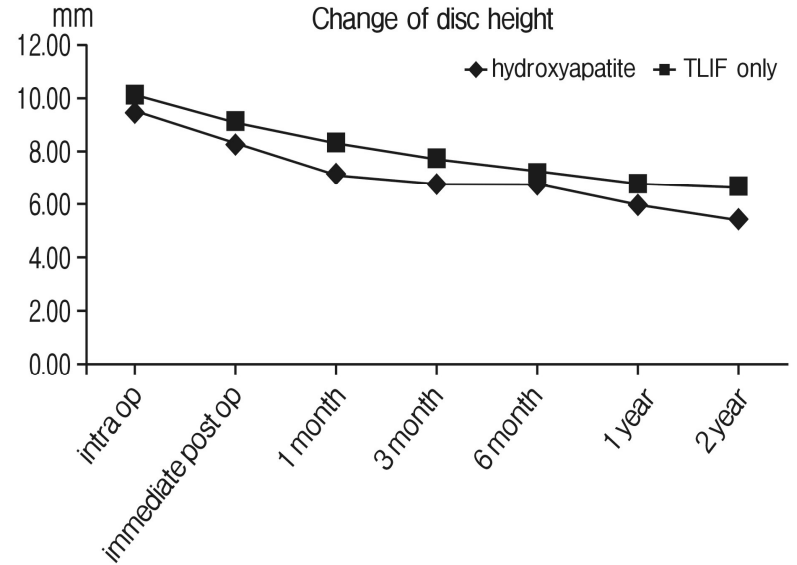

Fig. 4. The changes of posterior disc heights over serial follow-up. The mean posterior disc heights between the vertebral bodies at the operated level have significantly reduced from 9.48 $\mathrm{mm}$ to $5.39 \mathrm{~mm}$ for the augmentation group $(\mathrm{p}<0.05)$ and from $10.08 \mathrm{~mm}$ to $6.61 \mathrm{~mm}$ for the TLIF only group $(\mathrm{p}<0.05)$ without any significant difference between two groups.

Table 3. The amount of changes of the angles( $\left({ }^{\circ}\right)$ between upper and lower screws from index point to certain period during the follow-up

\begin{tabular}{|c|c|c|c|}
\hline & $\begin{array}{c}\text { Hydroxyapatite } \\
\text { group }\end{array}$ & $\begin{array}{l}\text { TLIF only } \\
\text { group }\end{array}$ & $p^{-v a l u e}{ }^{*}$ \\
\hline Intraop-immed. postop & $1.92 \pm 1.66$ & $1.26 \pm 0.87$ & $p>0.05$ \\
\hline Intraop- postop $1 \mathrm{mn}$ & $2.35 \pm 1.80$ & $2.22 \pm 1.63$ & $p>0.05$ \\
\hline Intraop - postop $3 \mathrm{mn}$ & $2.68 \pm 2.43$ & $2.50 \pm 1.75$ & $p>0.05$ \\
\hline Intraop - postop 6 mn & $3.02 \pm 2.46$ & $3.11 \pm 1.88$ & $p>0.05$ \\
\hline Intraop-postop $1 \mathrm{yr}$ & $3.21 \pm 2.20$ & $3.64 \pm 2.06$ & $p>0.05$ \\
\hline Intraop - postop $2 \mathrm{yr}$ & $4.05 \pm 2.69$ & $3.67 \pm 2.49$ & $p>0.05$ \\
\hline
\end{tabular}

Intraop: intraoperative, immed. postop: immediately after operation, mn: month, yr: year

*The degree of angle changes occurred from the index point to certain postoperative period showed no significant difference between two groups ( $p>0.05)$.

between two groups. The results of the changes in the posterior disc heights for each group are summarized in Figure 4.

\section{Angle changes between the upper and lower screws}

Although statistically not significant, the mean angle between the upper and lower screws showed gradual decrease from $14.86^{\circ}$ to $9.42^{\circ}$ for the TLIF only group while well maintained for the augmentation group from $9.62^{\circ}$ to $9.95^{\circ}$. However, the degree of angle changes occurred between each period or from the index point to certain postoperative period showed no significant difference between two groups. The results of the angle changes between the upper and lower screws for each group are summarized in Table 3 and Figure 5. 
Table 4. The amount of changes of the angles $\left(^{\circ}\right)$ between upper screw and lower end plate of L4 from index point to certain period and between certain time intervals during the follow-up

\begin{tabular}{lccc}
\hline \hline & Hydroxyapatite group & TLIF only group & $\mathrm{p}^{- \text {value }}$ \\
\hline Intraop - immed. Postop & $0.37 \pm 0.43$ & $1.17 \pm 1.35$ & $\mathrm{p}=0.048^{*}$ \\
Intraop - postop $1 \mathrm{mn}$ & $3.62 \pm 3.27$ & $1.82 \pm 1.57$ & $\mathrm{p}>0.05$ \\
Intraop - postop $3 \mathrm{mn}$ & $3.61 \pm 3.23$ & $2.69 \pm 1.82$ & $\mathrm{p}>0.05$ \\
Intraop - postop $6 \mathrm{mn}$ & $0.72 \pm 0.34$ & $3.17 \pm 1.89$ & $\mathrm{p}=0.003^{+}$ \\
Intraop - postop $1 \mathrm{yr}$ & $1.93 \pm 1.48$ & $2.40 \pm 1.75$ & $\mathrm{p}>0.05$ \\
Intraop - postop 2 yr & $2.07 \pm 1.30$ & $2.49 \pm 2.45$ & $\mathrm{p}>0.05$ \\
Intraop - immed. Postop & $0.37 \pm 0.43$ & $1.17 \pm 1.35$ & $\mathrm{p}=0.048$ \\
immed. Postop - postop 1 mn & $0.58 \pm 0.47$ & $0.99 \pm 0.65$ & $\mathrm{p}>0.05$ \\
postop $1 \mathrm{mn}$ - postop 3 mn & $0.78 \pm 0.12$ & $1.53 \pm 0.93$ & $\mathrm{p}=0.019^{* *}$ \\
postop $3 \mathrm{mn}$ - postop $6 \mathrm{mn}$ & $0.21 \pm 0.17$ & $1.42 \pm 0.94$ & $\mathrm{p}=0.001^{* *}$ \\
postop $6 \mathrm{mn}$ - postop $1 \mathrm{yr}$ & $0.93 \pm 1.02$ & $1.34 \pm 1.07$ & $\mathrm{p}>0.05$ \\
postop $1 \mathrm{yr}$ - postop $2 \mathrm{yr}$ & $0.64 \pm 0.45$ & $0.63 \pm 0.59$ & $\mathrm{p}>0.05$ \\
\hline
\end{tabular}

Intraop: intraoperative, immed. postop: immediately after operation, mn: month, yr: year

*Statistically significant degree of mean angle change of $1.17^{\circ}$ have occurred for the TLIF only group compared to $0.37^{\circ}$ for the augmentation group during the period between the index point and immediate postoperative period ( $p=0.048$ ).

${ }^{+}$More significant mean angle changes of $3.17^{\circ}$ have occurred for the TLIF only group over the period between the index point and postoperative 6 month $(\mathrm{p}=0.003)$.

* Statistically significant angle changes have occurred for the TLIF only group between 1 month and 6 months after the operation as the change between 1 month and 3 months for the TLIF only group was $1.53^{\circ}$ compared $0.78^{\circ}$ for the augmentation group $(p=0.02)$ and the change between 3 months and 6 months was $1.42^{\circ}$ for the former compared to $0.21^{\circ}$ for the latter group ( $p=0.001$ ).

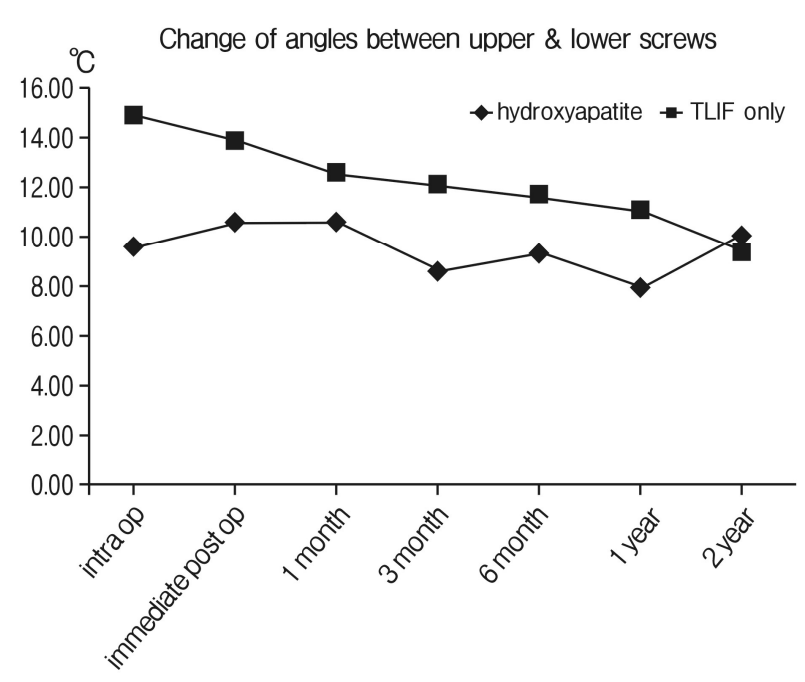

Fig. 5. The changes of angles between the upper and lower screws over serial follow-up. Although statistically not significant, the mean angle between the upper and lower screws showed gradual decrease from $14.86^{\circ}$ to $9.42^{\circ}$ for the TLIF only group while well maintained for the augmentation group from $9.62^{\circ}$ to $9.95^{\circ}(p>0.05)$.

\section{Changes of the angles between the upper screws and lower endplates of L4}

Statistically significant degree of mean angle change of $1.17^{\circ}$ between the upper screws and lower endplates of L4 occurred for the TLIF only group compared to $0.37^{\circ}$ for the augmentation group during the period between the index point and immediate postoperative period $(p=0.048)$. More significant angle changes have occurred for the TLIF only group over the period between the index point and postoperative 6 month $\left(3.17^{\circ}\right.$ for the TLIF only group vs $0.72^{\circ}$ for the augmentation group, $p=0.003$ ). Most of these significant angle changes seemed to have occurred for the TLIF only group between 1 month and 6 months after the operation as the change between 1 month and 3 months for the TLIF only was $1.53^{\circ}$ compared $0.78^{\circ}$ of the augmentation $(p=0.02)$ and the change between 3 months and 6 months was $1.42^{\circ}$ for the TLIF only compared to $0.21^{\circ}$ for the augmentation group $(p=0.001)$. Although it revealed that the mean angle change showed gradual decrease from $8.93^{\circ}$ to $5.79^{\circ}$ for the TLIF only group while well maintained for the augmentation group from $6.84^{\circ}$ to $6.93^{\circ}$, this difference was of no statistical significance $(p=0.053)$. The results of the angle changes between the upper screws and lower endplates of $L 4$ for each group are summarized in Table 4 and Figure 6.

\section{Changes of the angles between the lower screws and lower endplates of L5}

Compared to the changes in angle formed between the upper screws and lower endplates of $L 4$, the angles formed between the lower screws and lower endplates of L5 were relatively well maintained in both groups as the changes occurred only minimally from $11.3^{\circ}$ to $10.41^{\circ}$ for the augmentation group and 


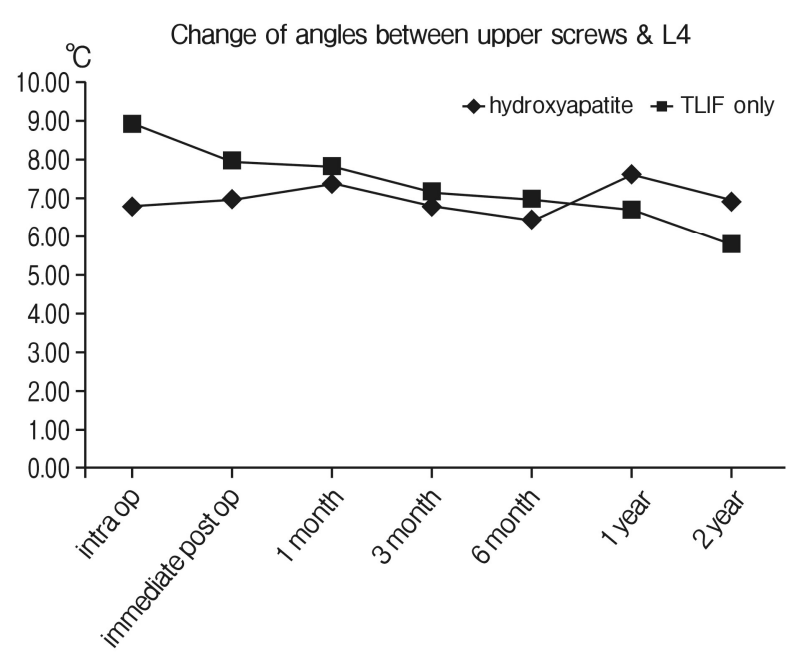

Fig. 6. The changes of angles between the upper screw and lower end plate of L4 over serial follow-up. Although it revealed that the mean angle change showed gradual decrease from $8.93^{\circ}$ to $5.79^{\circ}$ for the TLIF only group while well maintained for the augmentation group from $6.84^{\circ}$ to $6.93^{\circ}$, this difference was of no statistical significance $(p=0.053)$.

Table 5. The amount of changes of the angles ( $\left(^{\circ}\right)$ between lower screw and lower end plate of L5 from index point to certain period during the follow-up

\begin{tabular}{lccc}
\hline \hline & $\begin{array}{c}\text { Hydroxyapatite } \\
\text { group }\end{array}$ & $\begin{array}{c}\text { TLIF only } \\
\text { group }\end{array}$ & p-value \\
\hline Intraop-immed. postop & $0.62 \pm 1.07$ & $1.75 \pm 1.56$ & $\mathrm{p}>0.05$ \\
Intraop - postop $1 \mathrm{mn}$ & $1.26 \pm 1.25$ & $2.00 \pm 1.27$ & $\mathrm{p}>0.05$ \\
Intraop - postop $3 \mathrm{mn}$ & $1.37 \pm 1.38$ & $2.02 \pm 2.02$ & $\mathrm{p}>0.05$ \\
Intraop- postop $6 \mathrm{mn}$ & $0.67 \pm 0.32$ & $1.86 \pm 1.76$ & $\mathrm{p}>0.05$ \\
Intraop - postop 1 yr & $2.37 \pm 1.96$ & $1.66 \pm 1.52$ & $\mathrm{p}>0.05$ \\
Intraop - postop 2 yr & $2.91 \pm 2.00$ & $1.64 \pm 1.81$ & $\mathrm{p}>0.05$ \\
\hline
\end{tabular}

Intraop: intraoperative, immed. postop: immediately after operation, mn: month, yr: year

${ }^{*}$ The degree of angle changes occurred between each period or from the index point to certain postoperative period showed no significant difference between two groups ( $p>0.05$ ).

from $7.02^{\circ}$ to $6.99^{\circ}$ for the TLIF only group ( $p>0.05$ ). Consequently, the degree of angle changes occurred between each period or from the index point to certain postoperative period showed no significant difference between two groups. The results of the angle changes between the lower screws and lower endplates of L5 for each group are summarized in Table 5 and Figure 7.

\section{DISCUSSION}

Rigid fixation systems place high requirements on the loadcarrying capacity of the screw-bone interface. Poor bone quality decreases the integrity of this surface, increasing screw micromotion and reducing stability and possibly fusion success ${ }^{1)}$. In severely osteoporotic bone, pedicle screw use without supple-

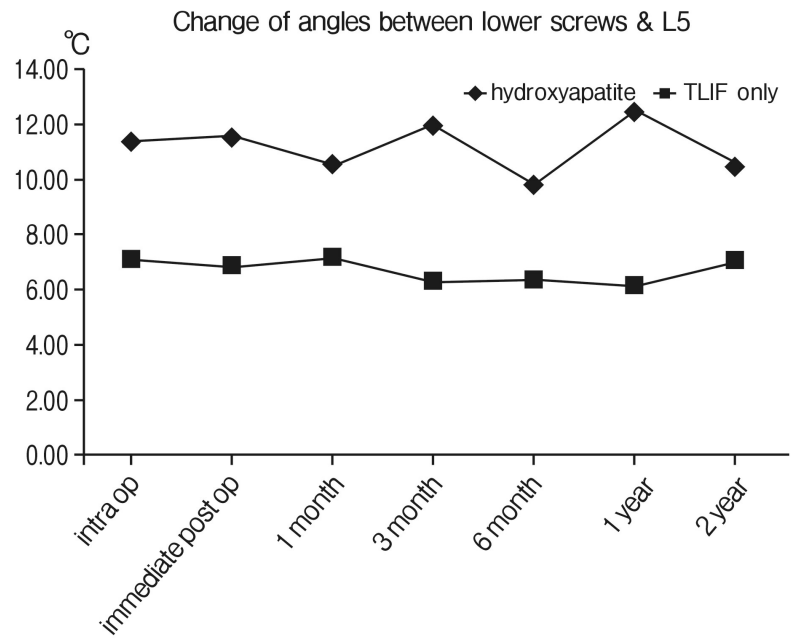

Fig. 7. The changes of angles between the lower screw and lower end plate of L5 over serial follow-up. The angles formed between the lower screws and lower endplates of $L 5$ were relatively well maintained in both groups as the changes occurred only minimally from $11.3^{\circ}$ to $10.41^{\circ}$ for the augmentation group and from $7.02^{\circ}$ to $6.99^{\circ}$ for the TLIF only group ( $\left.p>0.05\right)$.
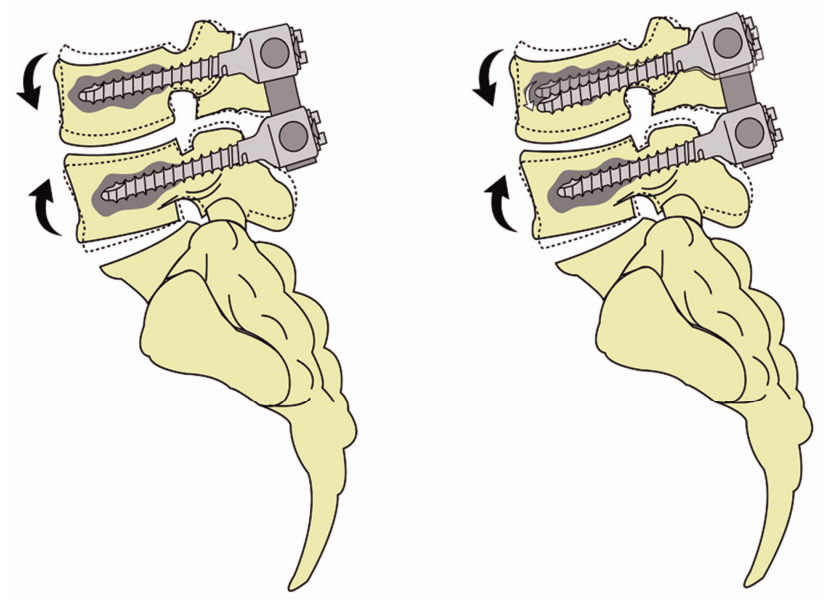

Fig. 8. An schematic illustration depicting statistically significant degree of mean angle change between the upper screws and lower endplates of L4 occurred for the TLIF only group (right) compared to the hydroxyapatite augmentation group (left) especially during the period between the index point and postoperative 6 month.

mentary augmentation might be precluded completely. Thus, a need exists for a measure to augment and strengthen the bone-screw interface that will reduce the risk of screw loosening and increase the endurance limit for pedicle screw fixation.

With this regard, the polymethyl methacrylate (PMMA) has been used in numerous animal or cadaveric studies in order to improve this implant fixation. The injection of PMMA was found to be effective augmentation method, increasing the pullout strength to approximately $150 \%$ of the initial pullout 
strength ${ }^{9)}$ and dramatically improve the resistance to screw toggle caused by cyclic caudocephalad loading ${ }^{5}$. However, although PMMA has been shown to significantly increase the pullout strength of pedicle screw fixation when inserted into the osteoporotic bones, there are several disadvantageous properties associated with the use of PMMA. These include the risk of tissue injury due to high exothermic polymerization temperature of 40 to $100^{\circ} \mathrm{C}^{10)}$, poor tolerance to fatigue, and its permanence in the body ${ }^{3)}$. Moreover, the pedicle screws augmented with PMMA are also very difficult to remove, greatly complicating revision surgery ${ }^{11)}$. Thus a biodegradable cement that has similar properties to PMMA, but that does not interfere with the natural bone healing or remodeling process, would be an attractive alternative for use in the augmentation of pedicle screws.

More recently, the suitability of nonexothermic, bioactive hydroxyapatite (HA) cements for pedicle screw augmentation has been investigated in this regard. Like PMMA, these cements can be injected or packed into irregular bony defects in the mixed, paste form. The injectable and in situ setting nature of this cement means that the cement-bone interface area is large which additionally contributes to the screw stability ${ }^{3,7)}$. Also, the HA cements are biocompatible and bioresorbable, meaning that they are initially osteotransductive with rapid ossointegration after implantation and later osteoconductive with promoting new bone replacement directly on the cement surface without intervening fibrous tissue ${ }^{8,12)}$, thereby forming a strong bond between bone and implant while allowing for simpler revision in the long-term ${ }^{13)}$. They solidify in minutes, and within four hours they attain $90 \%$ of their ultimate compressive strength, which is known to be as high as $60 \mathrm{Mpa}$ in 24-hour wet compressive strength ${ }^{14)}$. Moreover, unlike the polymerization of PMMA, the solidification of $\mathrm{HA}$ cement involves precipitation and is essentially nonexothermic ${ }^{7}$, thereby precludes the potential for thermal necrosis of adjacent tissue.

The result from the current study demonstrated that the statistically significant degree of mean angle change between the upper screws and lower endplates of $L 4$ occurred for the TLIF only group compared to the augmentation group especially during the period between the index point and postoperative 6 month (Fig. 8). Meanwhile, the angles formed between the lower screws and lower endplates of L5 were relatively well maintained in both groups. There are no proven results reported previously in the literature to interpret this phenomenon but our assumption would be that the upper level of the construct is more vulnerable to the cephalocaudad mechanical loadings that are being transferred to the screw construct during the daily activity especially before acquisition of solid bony fusion between two segments. This seems natural in mechanical point of view, as most of the cephalocaudad loading during the daily motion would be initially transferred to the upper body and screw and then to the interbody cage during the stage of one to six months after TLIF as the non-fused segments during this postoperative period would not be able to act as a single unit. As the previous series investigating the effects of the posterior spinal instrumentation on the adjacent motion seg- ments, the instrumented constructs produce higher segmental displacement values at the upper residual intact motion segment when compared with those of the intact spine, suggesting that more motion and loadings are being transferred to the upper level of the construct rather than lower level after fusion ${ }^{15}$. A more discrete biomechanical study such as the finite element analysis for the fused segments should be ensued to support this hypothesis.

In our surgical method, about $2 \mathrm{cc}$ of the solution of the HA cement powder mixed with sodium phosphate was injected through the each tapped hole using the needle typically used for vertebroplasty before inserting the actual screws. This is somewhat different from the method of coating the pedicular screws with plasma-sprayed HA that is frequently used in the previous literature ${ }^{16-18)}$, as the augmentation would only involve the central vertebral body and tip of the each screw rather than the pedicle or entire length of the screw. It is well known that the stiffness of the pedicle provides most of the stability, contributing $80 \%$ to cephalocaudad stiffness ${ }^{19)}$, with stiffness of the vertebral body of secondary importance ${ }^{9,20)}$. Moreover, reinforcing the entire screw-bone interface with cement has the advantage of increasing the compressive strength of the interface and it also increases the surface area of this interface ${ }^{3)}$, thereby decreasing the stress level. However, the result from the study by Renner et al. using the cadaveric model demonstrated that the average pull-out strength for the screws after injection of HA cement only to the distal tip of the screw hole was $1617 \mathrm{~N}$, which was not significantly different from 1852N measured after injection of HA cement along the entire length of the screw hole $\mathrm{e}^{21)}$. Since the initial stage of the screw loosening usually starts with the development of pendular motion at the screw tip and unlike the cancellous portion of the body, the density of the pedicle cortex usually maintains its stiffness even in the osteoporosis patients ${ }^{3}$, the authors presumed that the augmentation at the distal tip part of the screws would be sufficient enough to maintain its construct. Moreover, performing the fusion surgery sometimes require additional revision procedures due to untoward problem such as extravasation of the cement to spinal canal or screw or graft malpositioning or displacement, especially for the osteoporotic patients. By using the fully coated screws, the extraction would be extremely difficult as demonstrated by exceeding the range of torque wrench from the study by Sanden et al. ${ }^{22,23,24,25)}$. Therefore it may be possible to achieve an enhanced purchase of the screw to bone with relatively lower risk of violating the exterior cortex of the pedicle ${ }^{4,16)}$ and easier extraction of the screw in case of the revisional surgery by augmenting the distal tip of the screw only, as performed by the authors.

Since Caja and Moroni first described the improvement of the purchase of HA-coated implants from implantation to extraction after an experimental study of external fixation in sheep in $1996^{26)}$, numerous reports have demonstrated the excellence of $\mathrm{HA}$ in improving the mechanical properties of screw fixation by animal or cadaveric experimental model ${ }^{3,12,17,18,22-25,27)}$. However, these studies were focused on the ability of HA to obtain the 
rigid fixation immediately following the experimental surgery and there was no in vivo study examining its biocompatibility and effect on the biomechanical behavior after a long-term follow-up. In a study performed by Sanden et al. comparing the extraction torque of the screws either augmented with HA or not from the four actual patient 10 to 22 months after initial insertion, the extraction torques of the augmented screws far exceeded the range of torque wrench with the values significantly higher than $600 \mathrm{~N} \mathrm{~cm}$ compared to the standard screws with the values less than $5 \mathrm{~N} \mathrm{~cm}$, which is below the range of torque wrench ${ }^{22)}$. This study was similar to the concept of the current study as it demonstrated the well-maintained screwbone binding properties for the $\mathrm{HA}$-coated screws after certain time interval from the initial operation in actual patients. However, it has the limitation of merely measuring the screw mechanical property after performing only one screw-augmentation per each patient with proper vertebral body quality without demonstrating the ability of HA-coated screws in maintaining the entire screw construct especially in the patient with poor bone quality. In the current study, the authors have measured several indirect radiographic parameters to assess the maintenance of the screw construct at each follow-up interval because obtaining the mechanical parameters for measuring the screw purchase strength such as extraction torque requires additional surgery for each patient. Although the results derived from this measurement seems to be indirect assumption without any direct quantified results, the authors think that this method is sufficient enough to demonstrate the superiority of screw augmentation in maintaining the screw construct in the osteoporotic patient without requiring the additional surgery to verify this concept.

\section{CONCLUSION}

Both PMMA and hydroxyapatite are beneficial biomaterial to augment the instruments used during fusion surgery for these specific populations with osteoporosis. Unlike the heat producing polymerization process of PMMA, the solidification of hydroxyapatite $(\mathrm{HA})$ cement involves precipitation and is essentially nonexothermic, thereby precludes the potential for thermal necrosis of adjacent important neural tissue. Moreover, the HA cements are biocompatible and bioresorbable, thus facilitating the removal of pedicle screws augmented during revisional surgical events. Based upon our clinical series, most of the screw construct changes occurred in the upper level of fixation during 1 month to 6 months after fusion surgery in spondylolisthesis patients with osteoporosis. For these, the screw augmentation with HA demonstrated the improvement in maintaining the screw construct especially in the upper level of fixation.

\section{ACKNOWLEDGMENTS}

This study was sponsored by a fund from the Wooridul Spine Foundation. The screw augmentation during the current study was performed after obtaining the written consents from all the patients after they were explained as to the possible benefit that could be yielded with the use of the hydroxyapatite cement.

\section{REFERENCES}

1. Halverson TL, Kelley LA, Thomas KA, Whitecloud TS, Cook SD: Effects of bone mineral density on pedicle screw fixation. Spine 19:2415-2420, 1994

2. Moore DC, Maitra RS, Farjo LA, Graziano GP, Goldstein SA: Restoration of pedicle screw fixation with an in situ setting calcium phosphate cement. Spine 22:1696-1705, 1997

3. Turner AW, Gillies RM, Svehla MJ, Saito M, Walsh WR: Hydroxyapatite composite resin cement augmentation of pedicle screw fixation. Clin Orthop Relat Res 406:253-261, 2003

4. Pfeifer BA, Krag MH, Johnson C: Repair of failed transpedicle screw fixation. A biomechanical study comparing polymethylmethacrylate, milled bone, and matchstick bone reconstruction. Spine 19:350-353, 1994

5. Wittenberg RH, Lee K-S, Shea M, White AA, Hayes WC: Effect of screw diameter, insertion technique, and bone cement augmentation of pedicular screw fixation strength. Clin Orthop 296: 278-287, 1993

6. Cook SD, Salkeld SL, Whitecloud TS 3rd, Barbera J: Biomechanical evaluation and preliminary clinical experience with an expansive pedicle screw design. J Spinal Disord 13:230-236, 2000

7. Constantz BR, Ison IC, Fulmer MT, Poser RD, Smith ST, Van Wagoner M, Ross J, Goldstein SA, Jupiter JB, Rosenthal DI: Skeletal repair by in situ formation of the mineral phase of bone. Science 267:1796-1799, 1995

8. Driessens FC, Planell JA, Boltong MG, Khairoun I, Ginebra MP: Osteotransductive bone cements. Proc Inst Mech Eng $[\mathrm{H}]$ 212:427-435, 1998

9. Zindrick MR, Wiltse LL, Widell EH, Thomas JC, Holland WR, Field BT, Spencer CW: A biomechanical study of intrapedicular screw fixation in the lumbosacral spine. Clin Orthop 203:99-112, 1986

10. Konno S, Olmarker K, Byrod G, Nordborg C, Stromqvist B, Rydevik B: The European Spine Society AcroMed Prize 1994. Acute thermal nerve root injury. Eur Spine J 3:299-302, 1994

11. Wilkes RA, Mackinnon JG, Thomas WG: Neurological deterioration after cement injection into a vertebral body. J Bone Joint Surg $\mathrm{Br}$ 76:155, 1994

12. Fini M, Giavaresi G, Greggi T, Martini L, Aldini NN, Parisini P, Giardino R: Biological assessment of the bone-screw interface after insertion of uncoated and hydroxyapatite-coated pedicular screws in the osteopenic sheep. J Biomed Mater Res A 66:176183, 2003

13. Yerby SA, Toh E, McLain RF: Revision of failed pedicle screws using hydroxyapatite cement. A biomechanical analysis. Spine 23:1657-1661, 1998

14. Chow LC, Takagi S, Constantino PD: Self-setting calcium phosphate cements. Mat Res Symp Proc 179:3-24, 1991

15. Shono Y, Kaneda K, Abumi K, McAfee PC, Cunningham BW: Stability of posterior spinal instrumentation and its effect on adjacent motion segments in the lumbosacral spine. Spine 23: 1 550-1558, 1998

16. Cook SD, Salkeld SL, Stanley T, Faciane A, Miller SD: Biomechanical study of pedicle screw fixation in severely osteoporotic bone. Spine J 4:402-408, 2004

17. Hasegawa T, Inufusa A, Imai Y, Mikawa Y, Lim TH, An HS: 
Hydroxyapatite-coating of pedicle screws improves resistance against pull-out force in the osteoporotic canine lumbar spine model: a pilot study. Spine J 5:239-243, 2005

18. Yildirim OS, Aksakal B, Hanyaloglu SC, Erdogan F, Okur A: Hydroxyapatite dip coated and uncoated titanium poly-axial pedicle screws: an in vivo bovine model. Spine 31:E215-220, 2006

19. Hirano T, Hasegawa K, Takahashi HE, Uchiyama S, Tara T, Washio T, Sugiura T, Yokaichiya M, Ikeda M: Structural characteristics of the pedicle and its role in screw stability. Spine 22: 2504-2509, 1997

20. Lotz JC, Hu SS, Chiu DF, Yu M, Colliou O, Poser RD: Carbonated apatite cement augmentation of pedicle screw fixation in the lumbar spine. Spine 22:2716-2723, 1997

21. Renner SM, Lim TH, Kim WJ, Katolik L, An HS, Andersson GB: Augmentation of pedicle screw fixation strength using an injectable calcium phosphate cement as a function of injection timing and method. Spine 29:E212-216, 2004
22. Sanden B, Olerud C, Johansson C, Larsson S: Improved extraction torque of hydroxyapatite-coated pedicle screws. Eur Spine J 9:534-537, 2000

23. Sanden B, Olerud C, Larsson S: Hydroxyapatite coating enhances fixation of loaded pedicle screws: a mechanical in vivo study in sheep. Eur Spine J 10:334-339, 2001

24. Sanden B, Olerud C, Johansson C, Larsson S: Improved bonescrew interface with hydroxyapatite coating: an in vivo study of loaded pedicle screws in sheep. Spine 26:2673-2678, 2001

25. Sanden B, Olerud C, Petren-Mallmin M, Larsson S: Hydroxyapatite coating improves fixation of pedicle screws. A clinical study. J Bone Joint Surg Br 84:387-391, 2002

26. Caja VL, Moroni A: Hydroxyapatite coated external fixation pins: an experimental study. Clin Orthop 325:269-275, 1996

27. Rohmiller MT, Schwalm D, Glattes RC, Elalayli TG, Spengler DM: Evaluation of calcium sulfate paste for augmentation of lumbar pedicle screw pullout strength. Spine J 2:255-260, 2002 